\title{
Induction of tolerance against the arthritogenic antigen with type-II collagen peptide-linked soluble MHC class II molecules
}

\author{
Yoon-Kyung Park, Sundo Jung \& Se-Ho Park ${ }^{*}$ \\ Department of Life Sciences, Korea University, Seoul 02841, Korea
}

In murine collagen-induced arthritis (CIA), self-reactive $\mathrm{T}$ cells can recognize peptide antigens derived from type-II collagen (CII). Activation of $\mathrm{T}$ cells is an important mediator of autoimmune diseases. Thus, $\mathrm{T}$ cells have become a focal point of study to treat autoimmune diseases. In this study, we evaluated the efficacy of recombinant MHC class II molecules in the regulation of antigen-specific $T$ cells by using a self peptide derived from CII (CII260-274; IAGFKGEQGPKGEPG) linked to mouse $\mathrm{I}-\mathrm{A}^{\mathrm{q}}$ in a murine $\mathrm{CIA}$ model. We found that recombinant $1-A^{q} / C I I 260-274$ molecules could be recognized by Cll-specific $T$ cells and inhibit the same $T$ cells in vitro. Furthermore, the development of CIA in mice was successfully prevented by in vivo injection of recombinant $\mathrm{I}-\mathrm{A}^{\mathrm{q}} / \mathrm{CII} 260-274$ molecules. Thus, treatment with recombinant soluble MHC class II molecules in complex with an immunodominant self-peptide might offer a potential therapeutic for chronic inflammation in autoimmune disease such as rheumatoid arthritis. [BMB Reports 2016; 49(6): 331-336]

\section{INTRODUCTION}

Rheumatoid arthritis (RA) is a refractory autoimmune disease characterized by chronic synovitis that erodes adjacent cartilage, ultimately producing articular injury and ankylosis (1). Although the etiology of the disease remains largely unknown, there are cumulative findings suggesting an important role of the immune system in the inflammatory phase predominantly involving pathogenic T cell responses (2).

Collagen-induced arthritis (CIA) is an animal model for human RA. ClA can be induced by immunization with type-II collagen (CII), the major protein constituent of articular cartilage (3). In mice, the susceptibility to CIA appears to be asso-

${ }^{*}$ Corresponding author. Tel: +82-2-3290-3160; Fax: +82-2-9279028; E-mail: sehopark@korea.ac.kr

http://dx.doi.org/10.5483/BMBRep.2016.49.6.207

Received 13 October 2015, Revised 3 November 2015, Accepted 10 January 2016

Keywords: Collagen-induced arthritis, Immunotherapy, Rheumatoid arthriti, Recombinant MHC II, Type-II collagen ciated with MHC class II haplotypes $\mathrm{H}-2^{\mathrm{q}}$ and $\mathrm{H}-2^{\mathrm{r}}$, whereas in humans, susceptibility to RA is associated with MHC class II haplotypes DR1 and DR4 (4). The main histopathological features of the resulting joint inflammation in CIA are similar to those in RA, including proliferative synovitis, pannus formation, and cartilage or bone erosion $(1,5)$. Additionally, CIA and RA are both mediated by the activation of helper T cells expressing pro-inflammatory cytokines such as IFN- $\gamma, \mathrm{TNF}-\alpha$, IL-1 $\beta$, IL-6, and IL-17 (6-8).

Activation of naïve $\mathrm{CD}^{+}{ }^{+} \mathrm{T}$ cells is a multi-step process initiated by co-ligation of T cell receptor (TCR) and CD4 by the MHC class II/peptide complex presented on antigen presenting cells (APCs) (signal 1) and costimulation through other T cell surface molecules such as CD28 (signal 2) (9). However, stimulation of $\mathrm{CD}^{+}{ }^{+} \mathrm{T}$ cells without costimulatory signals induces anergy rather than activation (10-12). Moreover, T cells require multiple TCR engagements with antigen-loaded MHC molecules at the immunological synapse to receive sufficient signals for their activation. Receptor clustering involving multiple engagements between TCRs and MHC molecules induce cross-activation of TCR/CD3 complexes and mediate the propagation of intracellular signals necessary for $\mathrm{T}$ cell activation $(13,14)$. Thus, the engagement of TCRs with monomeric MHC/peptides does not usually provide sufficient activation signals. Rather, it induces anergy of the engaged T cells (15). Based on these findings, antigen-specific activation of pathogenic T cells with monomeric MHC/antigen in the absence of co-stimulatory signals has been considered as an immunotherapeutic approach for treating autoimmune diseases $(12,16$, 17). Therefore, it is possible that soluble MHC molecules loaded with specific auto-antigenic peptides can be recognized by autoimmune $T$ cells and induce the suppression or anergy of self-reactive $T$ cell clones.

In this study, we generated a recombinant molecule consisting of a single chain $\mathrm{I}-\mathrm{A}^{\mathrm{q}} \mathrm{MHC}$ class II molecule covalently linked to immunogenic peptides of CII260-274. In vivo delivery of the soluble form of this molecule in CIA-induced mice reduced the incidence and clinical signs of $\mathrm{CIA}$ by suppressing pro-inflammatory cytokines IFN- $\gamma$, IL-1 $\beta$, and IL-6. Moreover, the number of $\mathrm{CD} 4^{+}$pathogenic T cells was decreased in mice treated with recombinant soluble $\mathrm{I}-\mathrm{A}^{\mathrm{q}} / \mathrm{CII} 260-274$. This study will improve our current understanding on the role of pathogenic T cells in autoimmune disease. In addition, it might pro- 
vide a potential clinical use for treating RA in humans.

\section{RESULTS}

\section{Recombinant single chain $\mathrm{I}-\mathrm{A}^{\mathrm{q}} / \mathrm{CII260-274}$ is recognized by Cll-specific CD4 ${ }^{+}$T cells}

To evaluate the immunosuppressive effect of soluble monomeric MHC class II molecules, we produced a single chain murine $1-A^{q}$ molecule consisting of peptide binding domains ( $\alpha 1$ and $\beta 1$ ) and an immunogenic peptide of Cll260-274. Vector map for the production of single chain I-A ${ }^{q} / \mathrm{CII} 260-274$ molecule and the amino acid sequences of in vivo and in vitro versions of this molecule are shown in supplementary Fig. 1. Its in vitro version has an additional $6 \mathrm{X}$ His tag.

To test whether the recombinant single chain $\mathrm{I}-\mathrm{A}^{\mathrm{q}} / \mathrm{CII} 260$ 274 molecule maintained its specificity against CIl-specific $\mathrm{T}$ cells, an in vitro stimulation of Cll-specific T cells was performed using plate-coated I-A $/ \mathrm{Cll} 260-274$ to mimic membrane-expressed MHC II molecules. Cll-specific T cells were primed by $\mathrm{Cll}$ immunization in DBA 1 mice in which $\mathrm{ClA}$ was induced as described in Materials and Methods. Plates were coated with various concentrations of I-A $\% / C I I 260-274$. Cll-specific $\mathrm{CD}^{+}{ }^{+} \mathrm{T}$ cells from DBA/1 mice were incubated in these plates for $48 \mathrm{hr}$. The levels of IFN- $\gamma$ secreted by activated $\mathrm{CD}^{+}{ }^{+} \mathrm{T}$ cells into the supernatant were correlated with the concentration of $\mathrm{I}-\mathrm{A} / \mathrm{CII} 260-274$ used to coat the plates (Fig. 1A). This result indicated that Cll-specific T cells could recognize and respond to recombinant single chain I-A ${ }^{q} / \mathrm{CII} 260-274$ molecules.

\section{Recombinant soluble single chain $\mathrm{I}-\mathrm{A}^{\mathrm{q}} / \mathrm{CII} 260-274$ suppresses Ag-specific $\mathrm{CD4}^{+}$T cells}

Because it became evident that the plate-bound form of single chain $\mathrm{I}-\mathrm{A} / \mathrm{C}$ II $260-274$ molecules could be recognized by Cll260-274-specific T cells, next we determined whether soluble I-A $\%$ CII260-274 molecules could suppress Cll-specific T cells. To evaluate the suppressive effect of soluble I-A $\%$ CII260274 molecules, Cll-specific T cells were stimulated with gamma-ray-irradiated CII peptide-loaded APCs. Various amounts of soluble I-A $\mathrm{A}^{\mathrm{q}} / \mathrm{Cl} 260-274$ molecules were then added to the reaction. The levels of IFN- $\gamma$ in the culture supernatants after $48 \mathrm{hr}$ of incubation were significantly $(\mathrm{P}<0.0001)$ decreased when $2 \mu \mathrm{g}$ of soluble $\mathrm{I}-\mathrm{A}^{\mathrm{q}} / \mathrm{CII} 260-274$ was added, although up to $1 \mu \mathrm{g} /$ well of soluble I-A $\mathrm{q} / \mathrm{ClI} 260-274$ did not show a noticeable suppressive effect (Fig. 1B). We further determined the effect of soluble $1-\mathrm{A}^{\mathrm{q}} / \mathrm{CII} 260-274$ on the proliferation of Cll-specific $\mathrm{CD}^{+}{ }^{+}$T cells. Soluble I-A $\% / C I I 260-274$ by itself did not stimulate the proliferation of Cll-specific $\mathrm{CD}^{+}{ }^{+} \mathrm{T}$ cells (Fig. 1C). However, when soluble I-A ${ }^{q} / \mathrm{Cll} 260-274$ was added to Cll-specific T cells activated by plate-bound I-A $\mathrm{q} / \mathrm{CII} 260-274$, as low as $0.5 \mu \mathrm{g} /$ well of soluble $\mathrm{I}-\mathrm{A} \% \mathrm{Cll} 260-274$ suppressed $(\mathrm{P}<$ 0.05) the proliferation of Cll-specific T cells. Furthermore, treatment with $3 \mu \mathrm{g} /$ well of soluble I-A $/ \mathrm{ClI} 260-274$ completely blocked $(\mathrm{P}<0.01)$ the proliferation of Cll-specific $\mathrm{T}$ cells to the same level as in un-activated controls (Fig. 1C).

\section{Recombinant soluble single chain $\mathrm{I}-\mathrm{A}^{\mathrm{q}} / \mathrm{CII} 260-274$ treatment ameliorates $\mathrm{CIA}$}

To evaluate the effect of soluble I-A $\%$ CII260-274 on the suppression of Cll-specific $\mathrm{CD}^{+}{ }^{+} \mathrm{T}$ cell responses in vivo, we adopted a murine model of the human autoimmune disease RA. To induce $\mathrm{CIA}$, mice were immunized with $\mathrm{Cll}$ at day 0 . Mice then received i.v. injections of $100 \mu$ recombinant soluble single chain I-A $/$ CII260-274 on day 25, 27, and 29.

A

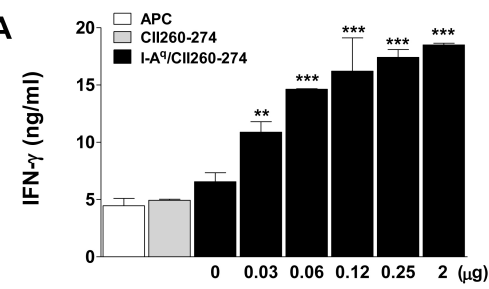

B

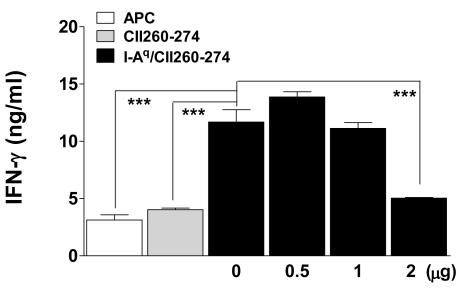

C

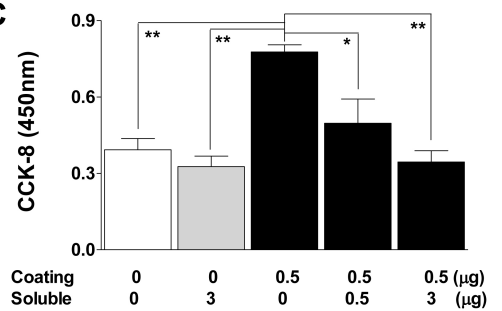

Fig. 1. Suppression of Ag-specific $T$ cells by recombinant soluble $\mathrm{I}-\mathrm{A}^{\mathrm{q}} / \mathrm{CII}$. (A) Bioactivity test of purified I-A $/ \mathrm{Cll} 260-274$ molecules. CII-specific T cells were stimulated at $37^{\circ} \mathrm{C}$ for $48 \mathrm{hr}$ in plates coated with various concentrations of recombinant I-A $\mathrm{A}^{\mathrm{q}} \mathrm{ClI} 260-274$ molecules (0-2 $\mu \mathrm{g} /$ well in 96-well plate). Cll-specific T cells stimulated with APC alone or CII260-274 (IAGFKGEQGPKGEPG) peptide alone were used as negative controls. Culture supernatants were collected and the concentrations of IFN- $\gamma$ were measured by ELISA. (B) DBA 1 splenocytes were incubated at $37^{\circ} \mathrm{C}$ for $24 \mathrm{hr}$. Plate bound cells were further incubated with CII260-274 peptide for $48 \mathrm{hr}$ at $37^{\circ} \mathrm{C}$ followed by irradiation with gamma-ray (3000 rad) to prepare APCs. Cll-specific T cells were stimulated with the prepared APCs for $48 \mathrm{hr}$ at $37^{\circ} \mathrm{C}$ in the presence of different concentrations of soluble $\mathrm{I}-\mathrm{A}^{\mathrm{q}} / \mathrm{CII} 260-274$ molecules. Supernatants were collected and the concentration of IFN- $\gamma$ was measured by ELISA. (C) CII-specific T cells were stimulated with plate-coated $\mathrm{I}-\mathrm{A}^{9} / \mathrm{CII260-274}$ as in (A) with various concentrations of soluble

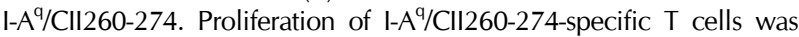
measured by using CCK- 8 as an indicator of cell activation. One-way ANOVA with Dunnett's multiple comparison tests were used to compare significant differences among groups: ${ }^{* * *} \mathrm{P}<0.0001$ or $\mathrm{P}<$ $0.001 ; * * P<0.01 ; * P<0.05$. 
ClA-induced mice treated with I-A $\% / C I I 260-274$ showed slightly reduced disease incidence (100\% vs. $75 \%)$ with significant reduction in disease symptoms $(\mathrm{P}<0.05)$ and delayed onset $(\mathrm{P}<0.01)$ compared to mock control (Fig. 2A, 2B). In addition, the histopathological signs of hind limbs at day 40 of disease induction were compared after $\mathrm{H}$ \& $\mathrm{E}$ staining. While ankle joints of hind limbs obtained from PBS treated group showed significant leukocyte infiltration and cartilage erosion, soluble $1-\mathrm{A}^{\mathrm{q}} / \mathrm{CII} 260-274$ treated group showed no significant sign of inflammation (Fig. 2C). The amelioration of arthritic index in mice treated with soluble I-A $/$ CII260-274 correlated with the decreased number of antigen-specific T cells (Fig. 3A, 3B). When splenic $T$ cells were stained with $\mathrm{I}-\mathrm{A}^{\mathrm{q}} / \mathrm{CII} 260-274$ dimer, ClA-induced control mice showed significantly $(\mathrm{P}<$

A

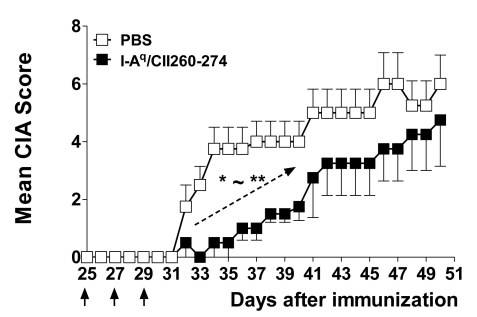

B

$\left.\begin{array}{ccc}\hline \text { Treatment } & \text { Incidence (\%) } & \text { Days of onset } \\ \hline \text { PBS } & 100 & 32.3 \pm 0.5 \\ \text { I-A } 9 \text { /CII260-274 } & 75 & 35.5 \pm 2.5\end{array}\right]$

C

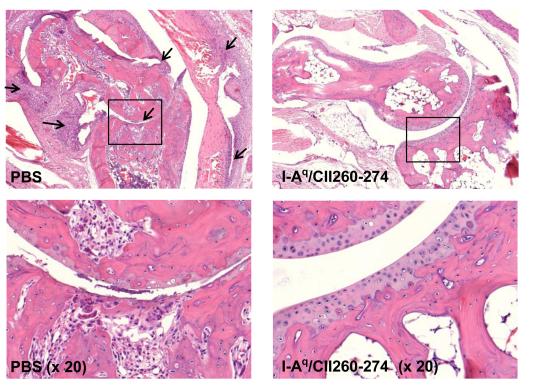

Fig. 2. Suppression of $\mathrm{ClA}$ by the treatment with recombinant soluble $\mathrm{I}-\mathrm{A}^{\mathrm{q}} / \mathrm{Cll}$. (A, B) CIA was induced in female DBA 1 mice as described in Materials and Methods. Mice were treated i.v. with soluble $\mathrm{I}-\mathrm{A}^{\mathrm{q}} / \mathrm{Cll} 260-274(100 \mu \mathrm{g}$ in $200 \mu \mathrm{l}$ of PBS) or PBS alone on day 25,27, and 29 (arrows, 4 mice per group). Incidence of CIA development, days of disease onset, and clinical scores were measured. In the assessment for the day of disease onset and clinical scores, mice without arthritic symptoms were excluded. Experiments were performed twice. They showed similar patterns. Data shown are from a representative experiment. CIA scores of experimental and control groups at given days and disease onset days were compared using Student's $t$-test. Days showing statistically significant $(P<0.05)$ differences were marked with an asterisk $\left.{ }^{*}\right)$. (C) Histological features of ankle joints from PBS or soluble single chain I-A $/ \mathrm{CII} 260-274$ treated mice at day 40 after disease induction. A representative picture of each group was shown.
0.05) increased number of Cll-specific T cells. However, lower numbers of $\mathrm{T}$ cells were observed in mice treated with soluble $\mathrm{I}-\mathrm{A}^{\mathrm{q}} / \mathrm{CII} 260-274$, similar to those in negative control mice without $\mathrm{CIA}$ induction. Furthermore, in in vitro $\mathrm{Cll}$ restimulated splenocytes, soluble I-A $\%$ CII260-274 treated group did not show any noticeable cell proliferation, unlike the CIA-induced control group (Fig. 3C).

\section{Recombinant soluble single chain $\mathrm{I}-\mathrm{A}^{\mathrm{q}} / \mathrm{CII} 260-274$ treatment reduces pro-inflammatory cytokine levels}

Next, we analyzed the effect of soluble I-A $\%$ CII260-274 treatment on cytokine production by Cll-specific T cells in vivo. Splenocytes from two experimental groups at day 50 were isolated, re-stimulated in vitro with Cll peptide, and analyzed for cytokine production. As shown in Fig. 4A, the levels of pro-inflammatory cytokines IL-1 $\beta$ and IL- 6 related to disease severity $(18,19)$ were significantly $(P<0.05)$ lower in the single chain $\mathrm{I}-\mathrm{A}^{\mathrm{q}} / \mathrm{CII} 260-274$ treated group compared to those in the control. Intracellular staining also showed a decrease in the number of IFN- $\gamma$-producing $\mathrm{CD} 4{ }^{+} \mathrm{T}$ cells in mice treated with soluble I-A $\mathrm{q} / \mathrm{Cll} 260-274$ compared to that in the control (Fig. $4 \mathrm{~B})$. In contrast, the frequencies of IL-4- and IL-10-producing $\mathrm{CD}^{+} \mathrm{T}$ cells were relatively larger $(\mathrm{P}<0.05)$ than those in the control group (Fig. 4B).

A

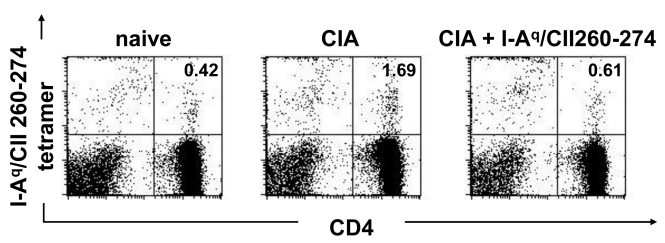

B

C
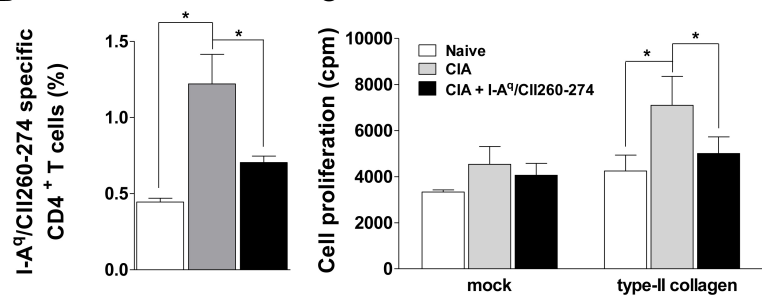

Fig. 3. Decreased numbers of Ag-specific $\mathrm{T}$ cells after treatment with recombinant soluble $\mathrm{I}-\mathrm{A} \% \mathrm{CII}$ molecules. (A) Splenocytes were collected from DBA 1 mice on day 50 after $\mathrm{ClA}$ induction and stained with $\mathrm{I}-\mathrm{A}^{\mathrm{q}} / \mathrm{CII} 260-274$ dimers, anti-CD4, and anti-TCR $\beta \mathrm{mAb}$. $\mathrm{TCR}^{+}$-gated cells were shown in figures. (B) Mean percentages of Cll-specific CD4 ${ }^{+} \mathrm{T}$ cells are shown. (C) Splenocytes from the indicated groups were restimulated with CII or PBS (mock) in vitro as described in Materials and Methods. One-way ANOVA with Dunnett's multiple comparison tests were used to compare significant differences among 3 groups: ${ }^{* * * P}<0.0001$ or $\mathrm{P}<$ $0.001 ;{ }^{*} \mathrm{P}<0.01 ;{ }^{*} \mathrm{P}<0.05$. 
A

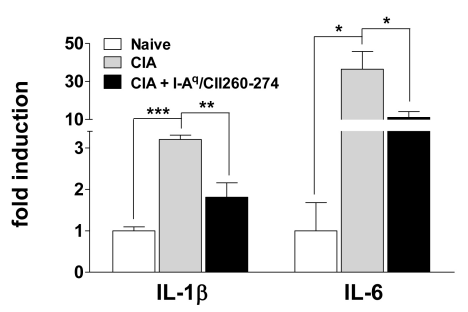

B

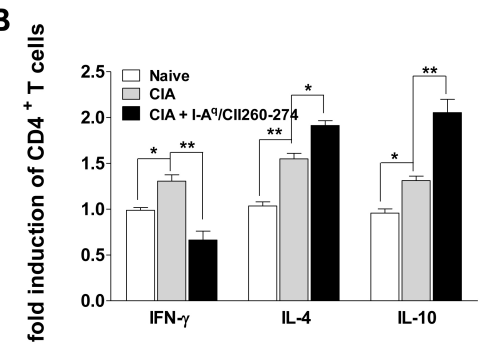

Fig. 4. Rebalance of pro- and anti- inflammatory cytokine production after treatment with recombinant soluble $\mathrm{I}-\mathrm{A}^{\mathrm{q}} / \mathrm{Cll}$ molecules in vivo. (A) Cytokines IL-1 $\beta$ and IL-6 in the supernatants of restimulated splenocytes from each group were measured by ELISA. (B) In vitro restimulated splenocytes were subjected to intracellular staining with anti-cytokine monoclonal Abs to measure intracellular cytokine levels of $\mathrm{CD}^{+} \mathrm{T}$ cells by flow cytometry. Data shown are representative results from three independent experiments with similar results. One-way ANOVA with Dunnett's multiple comparison tests were used to compare significant differences among 3 groups: ${ }^{* * *} \mathrm{P}<0.0001$ or $\mathrm{P}<0.001 ;{ }^{* *} \mathrm{P}<$ $0.01 ; * P<0.05$.

\section{DISCUSSION}

Rheumatoid arthritis is an autoimmune disease perpetuated by self-reactive pathogenic $\mathrm{CD}^{+}{ }^{+} \mathrm{T}$ cells (1). ClA is an animal model of RA and a model for Th1-mediated autoimmune diseases (6). In this model, Th2-derived anti-inflammatory cytokines have been shown to be able to ameliorate the disease. It has been proposed that rebalancing the immune response by increasing Th2 cells and suppressing Th1 cells could be beneficial for the treatment of $\mathrm{CIA}(20,21)$.

Monomeric TCR engagements excluding the cross-linking of TCRs can induce the apoptosis of T cells without inducing antigen-specific activation $(12,15)$. It has been demonstrated that partial activation of pathogenic T cells by stimulating Ag-specific TCRs in the absence of costimulation could induce anergy (12) or apoptosis $(16,17)$. Recombinant MHC/peptide antigen complexes (either for MHC class I or class II) can be generated to target antigen-specific T cells (22-24). The use of these $\mathrm{MHC}$ /peptide complexes as a direct approach for Ag-driven immunosuppression of autoimmune diseases has been previously studied $(9,23,25,26)$. In this study, we constructed and produced recombinant soluble single chain $\mathrm{I}-\mathrm{A}^{\mathrm{q}} / \mathrm{CII} 260-274$ molecules to suppress activated pathogenic
$\mathrm{CD}^{+}{ }^{+}$cells in ClA-induced DBA1 1 mice, a mouse model of human RA.

The plate-bound form of $\mathrm{I}-\mathrm{A}^{\mathrm{q}} / \mathrm{CII} 260-274$ induced TCR cross-linking of antigen-specific T cells and activated Cll-specific $\mathrm{T}$ cell clones. In contrast, the soluble form suppressed Cll-specific T cell clones. In vivo treatment with the soluble monomeric form of this molecule in CIA-induced mice showed reduced incidence, delayed onset $(P<0.01)$, and decreased ( $\mathrm{P}<0.01$ up to day 40 ) clinical signs of $\mathrm{CIA}$. Histopathological data were also correlated with the clinical signs of animals. We also observed decreases in the production of pro-inflammatory cytokines IFN- $\gamma, \mathrm{IL}-1 \beta$, and IL- 6 and increases in the production of anti-inflammatory cytokines IL-4 and IL-10 by Cll-specific CD4 ${ }^{+} \mathrm{T}$ cells compared to those of the control $\mathrm{ClA}$-induced mice sacrificed at the end of disease scoring (on day 50). However, in vivo treatment with single chain $1-\mathrm{A}^{\mathrm{q}} / \mathrm{CII} 260-274$ could not maintain the suppressive effect to a statistically significant level at the end of the scoring period, although the experimental group still showed lower disease score. These results provide an insight for the best therapeutic protocol for a long term suppression of T cell-mediated autoimmune disease by using soluble single chain MHC II molecules, including the duration of treatment effect and the intervals of treatment. Determining the best protocol for the dosages and treatment intervals of single chain I-A $/$ CII260-274 molecules in CIA model will provide a basis for the utilization of antigen-linked MHC II molecule as a therapeutic reagent. In conclusion, our results demonstrated that soluble single chain $\mathrm{I}-\mathrm{A}^{\mathrm{q}} / \mathrm{CII} 260-274$ molecules could protect mice against severe $\mathrm{ClA}$ by suppressing and anergizing pathogenic $\mathrm{CD} 4^{+} \mathrm{T}$ cell clones. Conversely, the rebalance of pro- and anti-inflammatory cytokine production by Cll-specific T cells through using soluble I-A $\% / C I I 260-274$ molecules may explain the ameliorated disease outcomes of $\mathrm{ClA}$-induced mice. Our results suggest that well-designed MHC-peptide monomers can be used therapeutically in humans to treat chronic inflammation associated with autoimmune diseases such as rheumatoid arthritis.

\section{MATERIALS AND METHODS}

\section{Mice}

DBA/1 mice were purchased from Charles River Laboratories (Japan). These animals were kept under specific pathogen-free conditions. They were used at 7-10 weeks of age. The experimental protocols were approved by the Laboratory Animal Care and Use Committee of Korea University.

\section{Expression of recombinant soluble mouse MHC class II}

The gene used for the expression of single chain I-A $/ \mathrm{CII} 260-274$ was constructed by connecting immunodominant CII260-274 (IAGFKGEQGPKGEPG) to beta 1 and alpha 1 domains of I-A ${ }^{q}$ with linkers TSGGGGSLVPRGSGGGGS and VD, respectively. For tetramer staining, another version (6X His tag was added at the end of alpha 1 domain) was constructed. These cloned genes 
were inserted into $\mathrm{pET} 21 \mathrm{~d}+$ expression vector and expressed in Escherichia coli using $1 \mathrm{mM}$ IPTG at $37^{\circ} \mathrm{C}$ for $4 \mathrm{hr}$. Inclusion bodies produced by the bacteria were isolated, denatured, refolded, and purified using methods described previously (27-29).

\section{Preparation of Antigen-specific T cells, CIA induction, and clinical scoring}

Mice were immunized intradermally (i.d.) at the base of the tail with $100 \mu \mathrm{g}$ CII (Sigma-Aldrich) emulsified with an equal volume $(50 \mu \mathrm{l})$ of CFA (Sigma-Aldrich) using standard protocols (30). Mice were booster immunized by i.d. injection of $100 \mu \mathrm{g}$ Cll emulsified with incomplete Freund's adjuvant (IFA) on day 21. Nine days later, mice were sacrificed to obtain splenocytes. These cells were restimulated with Cll peptide and IL-2 in vitro to obtain antigen (Ag)-specific CD4 ${ }^{+} \mathrm{T}$ cells.

Before $\mathrm{ClA}$ induction, DBA/1 mice were randomly divided into two treatment groups. Mice were either intravenously (i.v.) injected three times with $100 \mu$ g recombinant soluble $\mathrm{I}-\mathrm{A}^{\mathrm{q}} / \mathrm{CII} 260-274$ molecules dissolved in $200 \mu \mathrm{l}$ of PBS (experimental group) or PBS alone (control group) with 2 day intervals. Treated mice were monitored every other day for onset and development of arthritis until the end of the experiment. The clinical severity of arthritis was graded for each paw according to the following scale: $0=$ normal paws, $1=$ edema and erythema in only one digit, 2 = progressive edema or erythema in at least two digits, and 3 = severe edema/inflammation and erythema involving the entire paw. The average of macroscopic score was expressed as the cumulative value of all paws. The maximum possible score was 12 .

Tetramer staining and flow cytometric analysis Cll-specific $\mathrm{CD}^{+}{ }^{+} \mathrm{T}$ cells were stained with $\mathrm{I}-\mathrm{A}^{\mathrm{q}} / \mathrm{Cll} 260-274$ dimers in FACS staining buffer (PBS containing $0.1 \%$ BSA and $0.01 \%$ sodium azide). Cells were pre-incubated with anti-FcR- $\gamma$ mAb (2.4G2) and goat anti-mouse IgG-pure antibody to block non-specific antibody binding at $4^{\circ} \mathrm{C}$ for $20 \mathrm{~min}$. Monomeric I-A $\mathrm{q} / \mathrm{Cll} 260-274$ (4 $\mu \mathrm{g} /$ sample) containing a $6 \mathrm{X}$ His tag was incubated with a mouse monoclonal antibody specific to penta-His (QIAGEN cat. no. 34660) for $30 \mathrm{~min}$. The resulting dimer was added to cells and incubated for $2 \mathrm{hr}$. After washing the cells, anti-mouse IgG1-PE was added to produce tetramers. The tetramer-stained cells were analyzed on a FACSCalibur using CellQuest software (BD Biosciences).

\section{Measurement of $\mathrm{Cll}$-specific $\mathrm{T}$ cell responses in vitro}

To analyze cytokine response of Cll-specific T cells, splenocytes were harvested from mice at day 50 after the first CII immunization. Cells $\left(5 \times 10^{5}\right.$ cells/well in a 96-well flat-bottom plate) were restimulated in triplicates with $100 \mu \mathrm{g} / \mathrm{ml} \mathrm{Cll}$ or PBS alone (mock). After 48 or $72 \mathrm{hr}$, the supernatants were collected and assessed for the presence of cytokines by ELISA (OPTEIA Mouse cytokine set; BD Pharmingen).

For intracellular cytokine staining, at day 50 after the first im- munization, splenocytes were isolated from immunized mice. Cells $\left(5 \times 10^{5}\right.$ cells/well on 96 -well flat-bottom plate) were cultured with $100 \mu \mathrm{g} / \mathrm{ml} \mathrm{Cll}$ or mock for $48 \mathrm{hr}$ followed by the addition of Golgi stop (BD Pharmingen). After $6 \mathrm{hr}$, cells were harvested for intracellular cytokine staining. To determine the levels of intracellular cytokines, cells were initially stained with appropriate mAbs, fixed, permeabilized with Cytofix/Cytoperm solution (BD Pharmingen), and stained with APC or R-PE conjugated anti-IL-4, anti-IL-10, or anti-IFN- $\gamma$ mAbs at $4^{\circ} \mathrm{C}$ for 45 min. The percentage of cells expressing cytoplasmic IL-4, IL-10, or IFN- $\gamma$ was determined by flow cytometry.

\section{Cell proliferation assays}

Quantification of Cll-specific T cells were estimated in 96-well plates using Cell Counting Kit-8 (CCK-8; Dojindo) (31) or by treating with $0.25 \mu \mathrm{Ci}$ of $\left[{ }^{3} \mathrm{H}\right]$ thymidine (NEN). Briefly, cells were incubated with $0.25 \mu \mathrm{Ci}$ of $\left[{ }^{3} \mathrm{H}\right]$ thymidine for $6 \mathrm{hr}$ prior to $\beta$-counting. Incorporation of $\left.{ }^{3} \mathrm{H}\right]$ thymidine was measured with a MicroBeta 1450 Trilux Liquid Scintillation counter (Wallac). Data were presented as the average count per minute (cpm) from triplicates. All proliferation experiments were repeated at least three times.

\section{Histology}

Fixed joints were decalcified in formic acid and processed for paraffin embedding. Tissue sections ( $3 \mu \mathrm{m}$ in thickness) were stained with hematoxylin and eosin for histological signs. Histological analysis was conducted using AbionCRO (Seoul, Korea).

\section{Statistical analysis}

Prism software (GraphPad) was used for all statistical analyses. One-way analysis of variance (ANOVA) followed by Dunnett's multiple comparison tests were used to determine significant differences among 3 or more groups. Student's t-tests were used to determine significant differences between two groups. Throughout the text, figures, and legends, the following symbols were used to denote statistical significance: $* * * \mathrm{P}<$ 0.0001 or $\mathrm{P}<0.001 ;{ }^{*} \mathrm{P}<0.01$; and $* \mathrm{P}<0.05$.

\section{ACKNOWLEDGEMENTS}

We thank the staffs of Gyerim Experimental Animal Resource Center for animal care and technical assistance. This work was supported by a grant (NRF-2015R1A2A2A01008124) of the Basic Science Research Program funded by the National Research Foundation of Republic Korea and a grant from Korea University.

\section{REFERENCES}

1. Imboden JB (2009) The immunopathogenesis of rheumatoid arthritis. Annu Rev Pathol 4, 417-434

2. Firestein GS (2004) The T cell cometh: interplay between 
adaptive immunity and cytokine networks in rheumatoid arthritis. J Clin Invest 114, 471-474

3. Courtenay JS, Dallman MJ, Dayan AD, Martin A and Mosedale B (1980) Immunisation against heterologous type II collagen induces arthritis in mice. Nature 283, 666-668

4. Zanelli E, Gonzalez-Gay MA and David CS (1995) Could HLA-DRB1 be the protective locus in rheumatoid arthritis? Immunol Today $16,274-278$

5. Trentham DE, Townes AS and Kang AH (1977) Autoimmunity to type II collagen an experimental model of arthritis. J Exp Med 146, 857-868

6. Mauri $C$, Williams RO, Walmsley $M$ and Feldmann $M$ (1996) Relationship between Th1/Th2 cytokine patterns and the arthritogenic response in collagen-induced arthritis. Eur J Immunol 26, 1511-1518

7. Ortmann RA and Shevach EM (2001) Susceptibility to collagen-induced arthritis: cytokine-mediated regulation. Clin Immunol 98, 109-118

8. Miossec P and van den Berg W (1997) Th1/Th2 cytokine balance in arthritis. Arthritis Rheum 40, 2105-2115

9. Burrows GG (2005) Systemic immunomodulation of autoimmune disease using MHC-derived recombinant TCR ligands. Curr Drug Targets Inflamm Allergy 4, 185-193

10. Quill H and Schwartz RH (1987) Stimulation of normal inducer $\mathrm{T}$ cell clones with antigen presented by purified la molecules in planar lipid membranes: specific induction of a long-lived state of proliferative nonresponsiveness. J Immunol 138, 3704-3712

11. Schwartz RH (1996) Models of T cell anergy: is there a common molecular mechanism? J Exp Med 184, 1-8

12. Appel $H$, Seth NP, Gauthier $L$ and Wucherpfennig KW (2001) Anergy induction by dimeric TCR ligands. J Immunol 166, 5279-5285

13. Smith-Garvin JE, Koretzky GA and Jordan MS (2009) T cell activation. Annu Rev Immunol 27, 591-619

14. DeFord-Watts LM, Dougall DS, Belkaya S et al (2011) The CD3 zeta subunit contains a phosphoinositide-binding motif that is required for the stable accumulation of TCR-CD3 complex at the immunological synapse. J Immunol 186, 6839-6847

15. Appleman LJ and Boussiotis VA (2003) T cell anergy and costimulation. Immunol Rev 192, 161-180

16. Rhode PR, Burkhardt $M$, Jiao J, Siddiqui AH, Huang GP and Wong HC (1996) Single-chain MHC class II molecules induce $\mathrm{T}$ cell activation and apoptosis. J Immunol $157,4885-4891$

17. Nag B, Kendrick T, Arimilli S, Yu SC and Sriram S (1996) Soluble MHC II-peptide complexes induce antigen-specific apoptosis in T cells. Cell Immunol 170, 25-33

18. Mu CX, Liu GL, Tian H, Li YC and Huang YL (2014) [Effect of Tetramethyl pyrazine on serum levels of IL-1beta, IL-6, and IL-2, and NO and PGE2 in the synovial fluid of CIA rats: an experimental research]. Zhongguo Zhong Xi Yi Jie He Za Zhi 34, 214-217

19. Zhang Y, Ren G, Guo M et al (2013) Synergistic effects of interleukin-1beta and interleukin-17A antibodies on collagen-induced arthritis mouse model. Int Immunopharmacol 15, 199-205

20. Nakajima A, Seroogy CM, Sandora MR et al (2001) Antigen-specific T cell-mediated gene therapy in collagen-induced arthritis. J Clin Invest 107, 1293-1301

21. Morita Y, Yang J, Gupta R et al (2001) Dendritic cells genetically engineered to express IL-4 inhibit murine collagen-induced arthritis. J Clin Invest 107, 1275-1284

22. Savage $P$, Millrain $M$, Dimakou $S$, Stebbing J and Dyson J (2007) Expansion of CD8 ${ }^{+}$cytotoxic T cells in vitro and in vivo using MHC class I tetramers. Tumour Biol 28, 70-76

23. Huan J, Kaler LJ, Mooney JL et al (2008) MHC class II derived recombinant $\mathrm{T}$ cell receptor ligands protect DBA1Lac] mice from collagen-induced arthritis. J Immunol 180, 1249-1257

24. Mealey RH, Sharif A, Ellis SA, Littke MH, Leib SR and McGuire TC (2005) Early detection of dominant Env-specific and subdominant Gag-specific CD8 ${ }^{+}$lymphocytes in equine infectious anemia virus-infected horses using major histocompatibility complex class $1 /$ peptide tetrameric complexes. Virology 339, 110-126

25. Offner $H$, Sinha $S$, Wang $C$, Burrows GG and Vandenbark AA (2008) Recombinant T cell receptor ligands: immunomodulatory, neuroprotective and neuroregenerative effects suggest application as therapy for multiple sclerosis. Rev Neurosci 19, 327-339

26. Huan J, Subramanian S, Jones R et al (2004) Monomeric recombinant TCR ligand reduces relapse rate and severity of experimental autoimmune encephalomyelitis in SJL/J mice through cytokine switch. J Immunol 172, 4556-4566

27. Kotzin BL, Falta MT, Crawford F et al (2000) Use of soluble peptide-DR4 tetramers to detect synovial T cells specific for cartilage antigens in patients with rheumatoid arthritis. Proc Natl Acad Sci U S A 97, 291-296

28. Lovitch SB, Pu Z and Unanue ER (2006) Amino-terminal flanking residues determine the conformation of a peptide-class II MHC complex. J Immunol 176, 2958-2968

29. Ren D, Wang F, He X et al (2006) Construction of bioactive chimeric MHC class I tetramer by expression and purification of human-murine chimeric MHC heavy chain and beta(2)m as a fusion protein in Escherichia coli. Protein Expr Purif 50, 171-178

30. Brand DD, Latham KA and Rosloniec EF (2007) Collageninduced arthritis. Nat Protoc 2, 1269-1275

31. Park J, Bae EK, Lee C et al. (2014) Establishment and characterization of bortezomib-resistant U266 cell line: constitutive activation of NF-kappaB-mediated cell signals and/or alterations of ubiquitylation-related genes reduce bortezomib-induced apoptosis. BMB Rep 47, 274-279 